\title{
Introduction to special issue Translational goals of neoadjuvant therapy
}

\author{
Stefan Glück
}

Published online: 22 March 2012

(C) Springer Science+Business Media, LLC. 2012

Data from NSABP B-18 [1] have clearly shown that systemic chemotherapy, delivered prior to (neoadjuvant) or after definite surgery (adjuvant) for early breast cancer leads to identical long-term outcomes. This was later confirmed with a meta-analysis [2] and reassured all of us that we can offer this timing of therapy to our patients.

So, what are the disadvantages? We are losing the exact pathologic anatomic staging; some of our patients will not tolerate the idea of still having the cancer in their body and wait for several months for definite surgery; a few cancers will not respond and threaten to spread beyond the breast and loco-regional lymph nodes. What we do gain is actually more: the possibility to downstage and improve operability (mastectomy vs. less invasive surgery); an in vivo sensitivity test to our therapy; gain an extremely strong surrogate marker for long-term outcome (low residual tumor burden); have a model to develop new compounds for clinical use; and most importantly, the opportunity to individualize therapy according to the biology and response to therapy, e.g., change compounds in the middle of the course of treatment and adjust our strategy against the disease, thus avoiding unnecessary and toxic therapy.
In this issue, two of the most influential experts in the field of neoadjuvant therapy, Debashish Tripathy and Gunter von Minckwitz, have selected a number of studies with data that includes very innovative translational components and will provide the reader with advanced scientific results in this exciting and fast-growing strategy to treat early breast cancer. These and similar data will lead to a better understanding of the biology of early breast cancer, empower us to use a more personalized approach, and ultimately, improve outcomes for our patients with breast cancer.

\section{References}

1. Fisher B, Brown A, Mamounas E, Wieand S, Robidoux A, Margolese RG, Cruz AB Jr, Fisher ER, Wickerham DL, Wolmark N, DeCillis A, Hoehn JL, Lees AW, Dimitrov NV (1997) Effect of preoperative chemotherapy on local-regional disease in women with operable breast cancer: findings from National Surgical Adjuvant Breast and Bowel Project B-18. J Clin Oncol 15(7):2483-2493

2. Mauri D et al (2005) J Natl Cancer Inst 97(3):188-194
S. Glück $(\bowtie)$

Division of Hematology/Oncology, Department of Medicine, Sylvester Comprehensive Cancer Center, Leonard M. Miller School of Medicine, University of Miami, 1475 NW 12th Ave., Miami, FL 33136, USA

e-mail:sgluck@med.miami.edu 